\title{
Effect of surface characteristics on capillary flow in triangular microgrooves
}

\author{
Tsung-Sheng Sheu, Pei-Pei Ding, I-Ming Lo, Ping-Hei Chen * \\ Department of Mechanical Engineering, National Taiwan University, No. 1 Sec. 4 Roosevelt Road, Taipei 10617, Taiwan, ROC \\ Received 7 April 2000; received in revised form 17 May 2000; accepted 10 June 2000
}

\begin{abstract}
The present work aims to study the effect of surface characteristics on the maximum wetted axial length $\left(x_{\max }\right)$ of a triangular microgrooves plate. A series of triangular microgrooves with upper width $(W)$ of $0.4 \mathrm{~mm}$ and the vertex angle $(\alpha)$ of $60^{\circ}$ was machined on oxygen-free copper plate. The measured microgrooves plates include one with non-etched surface texture with lined incisions left by machining tool, and another with chemically etched surface texture with micro cavities. Methanol and ethanol were used as working fluid. The tilt angles of test device $(\beta)$ and the applied heat flux $\left(q_{\mathrm{b}}^{\prime \prime}\right)$ were varied for measurement. The present result shows that the surface texture with micro cavities will have $10-35 \%$ longer wetted axial length as compared with surface texture with lined incisions. The surface texture performed by chemical etching is effective in increasing the capillary performance of low surface tension fluid. A baseline check shows good agreement among the present experimental result and previous study. (C) 2000 Elsevier Science Inc. All rights reserved.
\end{abstract}

Keywords: Capillary flow; Heat transfer; Triangular microgroove; Wetted axial length; Roughness characteristics

\section{Introduction}

The advancements of semiconductor industry and packaging technology in recent years have led to the miniaturization and increasing density of electronics component. The unit chip heat flux has been tremendously raised with the promoted functions of individual component. Hence, thermal management becomes a crucial technique that is related to the performance, reliability and cost of a product. The heat pipe based on the phase change heat exchange theory has been miniaturized and adopted as a heat dissipation component in these electronics equipment recently, especially for heat pipe with groove wicks that is easier to be manufactured in miniature range. Besides, studies on miniature heat pipe [1] and micro heat pipe [2] have also been developed to deal with the increasing heat flux and temperature uniformity problem in the future. Microgrooves are used as wicks in the inner surface to effectively promote the evaporation and condensation rates at both the evaporator and condenser ends. The capil\footnotetext{
4871.

${ }^{*}$ Corresponding author. Tel.: +886-2-2362-1522; fax: +886-2-2364-

E-mail address: phchen@ccms.ntu.edu.tw (P.-H. Chen).
}

lary forces of thin film on the grooves also provide pumping power for the circulation of condensed fluid from the condenser to evaporator. Therefore, the understanding on flow behavior of working fluid in the wicks is important in the design of a heat pipe. From the viewpoint of mechanical engineering, the investigations on the overall heat transfer and fluid mechanics on the microgroove surface are crucial for the improvement of heat pipe efficiency.

The initial contact of working fluid on the microgroove surface forms very small meniscus. As described by Holm and Goplen [3], the spreading of fluid on the microgroove surface can be classified into the three regions showed in Fig. 1 including the equilibrium thing film region, the evaporating thin film region and the intrinsic meniscus region. The forces in the equilibrium thin film region are dominated by disjoining pressure. The disjoining pressure would prevent evaporation, and therefore no wall heat flux could be brought away. For the evaporating thin film region, both the disjoining pressure and capillary force are the dominant forces. However, the effects of disjoining pressure on evaporation and heat transfer have diminished in this region. The capillary force becomes the dominant force and the effect of adhesion force in the thin film on the evaporation rate can be neglected in the intrinsic meniscus 


\begin{tabular}{|c|c|c|}
\hline Nomenclature & $x$ & the wetted axial length of microgrooves $(\mathrm{mm})$ \\
\hline A constant defined in Eq. (2) & \multirow{2}{*}{\multicolumn{2}{|c|}{ Greek symbols }} \\
\hline constant defined in Eq. (2) & & \\
\hline constant defined in Eq. (3) & $\begin{array}{l}\alpha \\
\beta\end{array}$ & the tilt angle of test device (degree) \\
\hline gravitational acceleration $\left(\mathrm{m} / \mathrm{s}^{2}\right)$ & $\rho$ & density $\left(\mathrm{kg} / \mathrm{m}^{3}\right)$ \\
\hline $\begin{array}{ll}h_{f g} & \text { latent heat of vaporization }(\mathrm{J} / \mathrm{kg}) \\
K & \text { the friction coefficient by Ayyaswamy et al. }[11]\end{array}$ & & surface tension $(\mathrm{N} / \mathrm{m})$ \\
\hline heat flux normal to the bottom plate $\left(\mathrm{W} / \mathrm{m}^{2}\right)$ & \multicolumn{2}{|r|}{ Subscript } \\
\hline $\begin{array}{l}\text { average roughness of microgrooves surface } \\
(\mu \mathrm{m})\end{array}$ & $\mathrm{j}$ & $\begin{array}{l}\text { junction of the adiabatic and evaporating } \\
\text { regions }\end{array}$ \\
\hline $\begin{array}{l}\text { radius of curvature in the intrinsic meniscus at } \\
x(\mathrm{~mm})\end{array}$ & $\begin{array}{l}1 \\
\max \end{array}$ & liquid \\
\hline temperature $\left({ }^{\circ} \mathrm{C}\right)$ & & 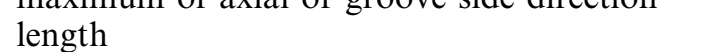 \\
\hline the upper width of microgrooves $(\mathrm{mm})$ & sat & saturation \\
\hline
\end{tabular}

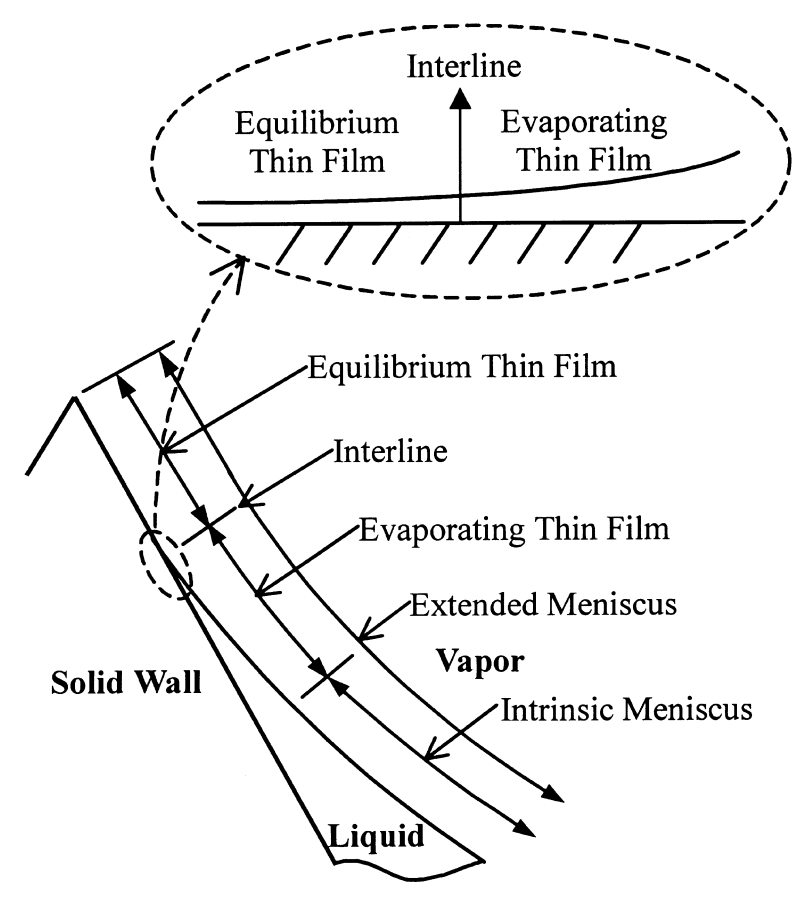

Fig. 1. Regions of the meniscus on microgroove surface.

region. The increased film thickness will increase the thermal resistance and change the heat transfer phenomenon. According to Rank and Wayner [4], the ranges of film thickness for the three regions are approximately estimated as $5 \times 10^{-8},(0.05-10) \times 10^{-6}$ and $>10^{-5} \mathrm{~m}$.

Some analytical models and experimental aspects on evaporation of thin liquid film on a flat plate have been extensively investigated in the literature, such as the studies of Potash and Wayner [5], Wayner et al. [6], Renk and Wayner [4,7], Mizamoghadam and Catton [8], Schonberg and Wayner [9], and DasGupta et al. [10]. Although these works have clarified some physical mechanism of the microgroove evaporation flow, it is still not sufficient for application. For the evaporation flow field in microgroove, the heat transfer and flow phenomena of the intrinsic meniscus in both axial and cross-sectional directions should be investigated.

The analytical model of the evaporation flow in microgrooves has been presented in several studies. Ayyaswamy et al. [11] saluted the two-dimensional equations of triangular grooves by the Galerkin boundary method; the independent parameters include contact angle and the half angle of microgrooves. Holm and Goplen [3] constructed a one-dimensional analytical heat transfer model of capillary trapezoid grooves to investigate the effects of groove spacing and heat transfer on interline. Stephan and Busse [12] solved the two-dimensional heat transfer conduction model to estimate the shape of liquid-vapor interface and temperature distribution in microgrooves. The influences of interfacial thermal resistance, disjoining pressure and surface roughness on the heat transfer coefficient were investigated by Khrustalev and Faghri [13]. The comparison on their numerical results and experimental data confirmed that these parameters have great influences on surface heat transfer. Ha and Peterson [14] derived an algebraic equation to estimate the dryout point in the triangular microgrooves, and a theoretical model for very small tilt angles were constructed by perturbation method later [15]. The intrinsic meniscus variation along the axial direction of the $\mathrm{V}$-shape microgroove was investigated in both studies.

$\mathrm{Xu}$ and Carey [16] studied the heat transfer characteristics of thin liquid film evaporation on the surface of V-shape microgrooves. Stroes et al. [17] compared the capillary performance of grooves by the experimental results of small triangular and rectangular grooves. The wetted axial lengths of different heat flux and tilt angle were also estimated using simplified models. The wetted axial length was proved to be a function of the input heat flux, the thermophysical properties, and the geometric parameters. Moreover, Peterson and $\mathrm{Ha}$ [18] estimated the dryout location in the triangular grooves by the closed-form solution of a simplified governing equation. The estimated results were also verified by experimental investigation. Sheu et al. [19] predicted the 
wetted axial length of trapezoid microgroove by both analytical and experimental models.

For most of the past literature, the triangular shape microgroove has been taken as the physical and experimental model in the study of heat transfer characteristics of thin liquid film. However, a perfectly smooth wall surface was assumed in most of these works, few researchers have put efforts on the effect of surface characteristics on the heat transfer phenomenon of thin liquid film. Hence, the present study estimates the wetted axial length and the dryout location of working fluid in triangular microgrooves of various surface textures according to the experimental setup as described by Peterson and $\mathrm{Ha}$ [18]. The surface of microgrooves was chemically etched to change the surface characteristics. The influence of roughness characteristic on the wetted axial length of microgrooves with different working fluid, ethanol and methanol, was investigated in the present study.

\section{Experimental description and procedure}

The main purpose of the present work is to measure the maximum wetted axial length $\left(x_{\max }\right)$ from the origin to the dryout point on the microgrooves as shown in the physical model illustrated in Fig. 2 [18]. The test device was tilted at an angle of $\beta$ with the adiabatic region at one end immersed in the working fluid, and a uniform heat flux were supplied to the base of evaporating region at the other end. Ethanol and methanol with lower free energy were used as the working fluid in the present study. The capillary forces will act against the frictional and gravitational forces, and pump the working fluid into the microgrooves on the test device.

The present experimental setup and procedure are similar to the work of Peterson and Ha [18]. The schematic view of the present experimental setup is shown in Fig. 3. A flexible thermofoil heater that attached to the base of the microgrooves plate provided a uniform heat flux of the evaporating region for a microgrooves plate. The thermofoil heater (Minco) has a resistance of 84.3 $\Omega$ and was activated by a DC power supply. A digital multimeter measured the input power of the heater with an uncertainty of $\pm 0.01 \mathrm{~W}$. The adjustments of tilt angle and the height of test device were performed by a

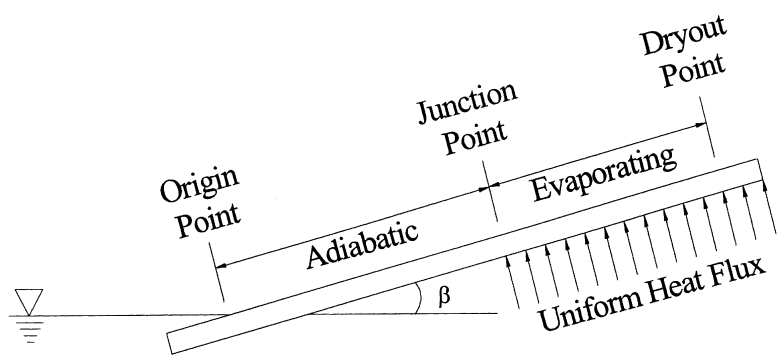

Fig. 2. Physical model of microgroove evaporation system.

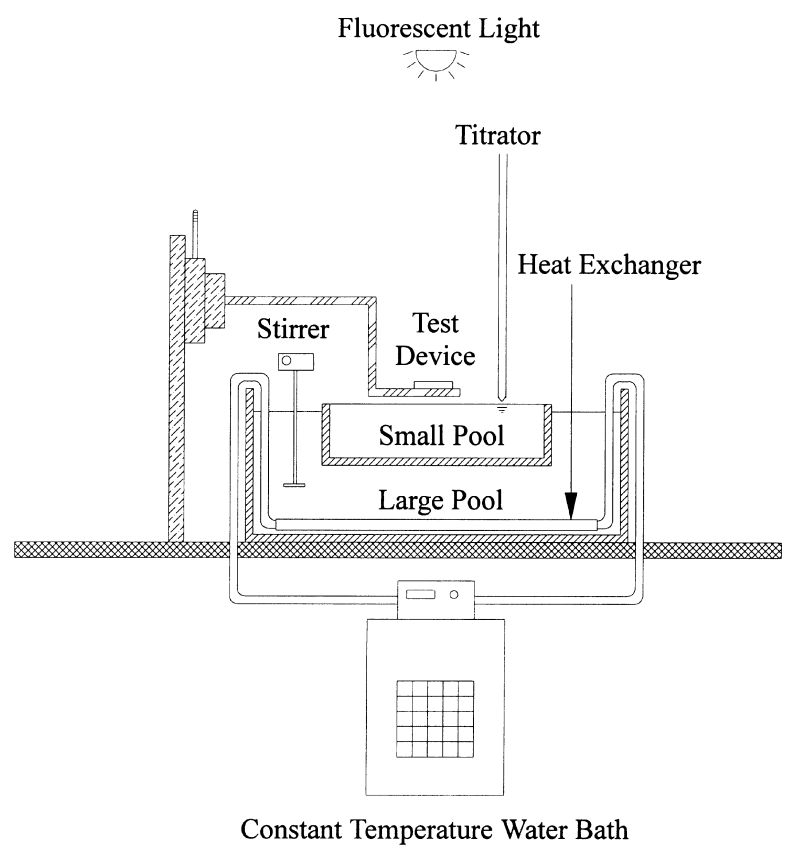

Fig. 3. Schematic view of experimental setup.

precise rotational and two-axis translational positioning mechanism. The working fluid in a small pool was maintained at a fixed level by titration during the measurement. A fluorescent light was used for convenience of observation during the estimation of wetted axial length.

The test device consists of a microgrooves plate, a heater and an insulation layer is shown in Fig. 4(a). Fig. 4(b) shows the $60 \mathrm{~mm} \times 20 \mathrm{~mm}$ microgrooves plate made by oxygen-free copper with a thickness of $5 \mathrm{~mm}$ in the evaporating region and a thickness of $2 \mathrm{~mm}$ in the adiabatic region. The former region is thicker to ensure that the uniformity of heat flux on the surfaces of microgrooves. Oppositely, the adiabatic region was made thinner to minimize the heat loss by conduction along the axial direction. Silicone heat transfer compound (Unick, UH-102) was applied to the base of microgrooves plate to reduce thermal resistance at the contact surface with the heater. Both sides of the microgrooves plate and the lower surface of the heater were insulated by fiberglass with thermal conductivity $0.035 \mathrm{~W} / \mathrm{mK}$ to prevent heat loss.

Two holes of diameter $0.5 \mathrm{~mm}$ with depth $10 \mathrm{~mm}$ were transversely drilled on each side of microgrooves plate at $1 \mathrm{~mm}$ below the evaporating region. The thermocouples of type $\mathrm{T}$ (Omega) with diameter $0.025 \mathrm{~mm}$ were embedded in these holes for temperature measurement. Moreover, two thermocouples were, respectively, embedded in the insulation layer at a distance of $5 \mathrm{~mm}$ and $10 \mathrm{~mm}$ away from the heater to estimate the heat loss through the insulating layer. The measured temperatures were recorded by a data logger. From the input power and the estimated heat loss, the total heat flux on the microgrooves surface can be obtained. 


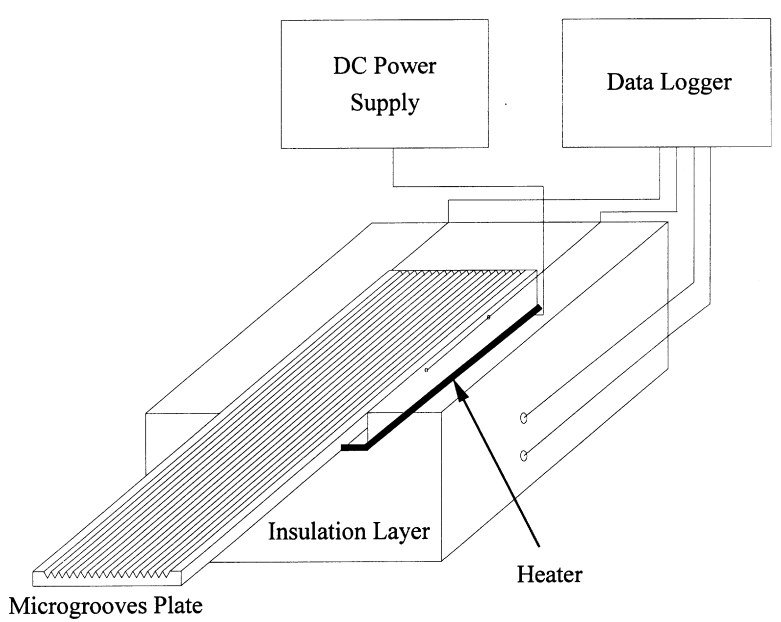

(a)

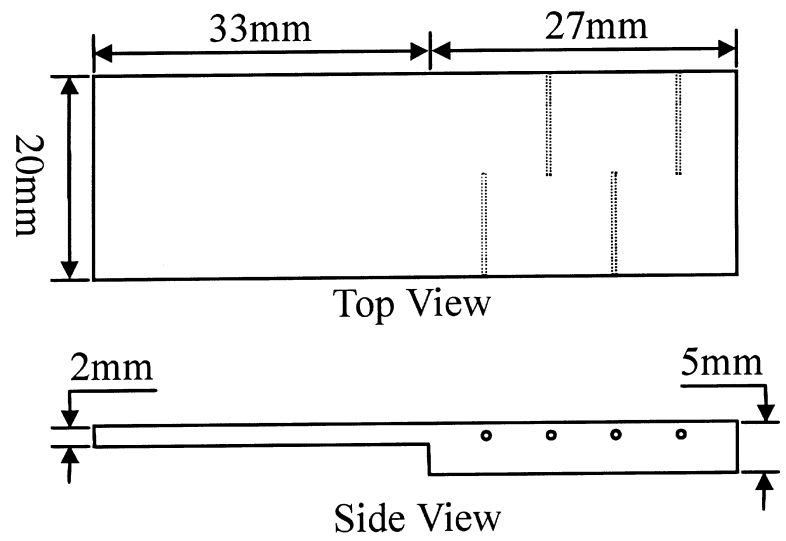

(b)

Fig. 4. (a) Test device; (b) top and side views of the microgrooves plate.

According to the estimation, the heat losses through the sidewalls and base of test device can be neglected as compared to the heat flux provided by the thermofoil heater.

The 50 triangular microgrooves were machined on the plate with a total region of $10 \mathrm{~mm}$ wide. The upper width of each triangular microgroove $(W)$ is $0.4 \mathrm{~mm}$, and the vertex angle $(\alpha)$ is $60^{\circ}$. Two types of surface texture were used in the present study to investigate the effect of microgroove surface characteristics on the maximum wetted axial length of heated capillary microgrooves. The surface texture of the non-etched test device was the original surface texture left by machining tool, and the surface texture of the etched test device was further rough with surface etching by using nitric acid solution. To discuss the microgroove surface characteristics, the surface texture was qualitatively observed using a scanning electron microscope (SEM). For the quantitative analysis, the profile measurement performed by an optical surface profilometer (ZYGO Maxim 3D 5700) was considered.

The surface characteristics of microgroove will cause severe effects on the maximum wetted axial length of the capillary flow. Any dust or oxidized layer can affect the wettability of working fluid on the microgroove surface too. Hence, a cleansing procedure of test device includes washing away of grease by acetone, pickling of oxidized layer by a $10 \%$ nitric acid solution, a rinse in distilled water, and finally drying by nitrogen gas to prevent oxidation is necessary for each measurement.

The measurement of the present study was conducted under an open environment. The temperature of environment was controlled within a variation of $\pm 3^{\circ} \mathrm{C}$ by a digital temperature controller (TOHO Electronics, TTM-100) to reduce the influence of the environment temperature on the evaporating process during measurement. A stable environment temperature must be achieved and maintained for each measurement. Under the present experimental setup, the evaporation of liquid would not create a pure vapor environment. Hence, the temperature measured on the microgroove surface is assumed to be the vapor saturation temperature. During measurement, one end of the test device was merged into a small pool filled with working fluid. To prevent axial heat transfer on the test device, the liquid temperature of small pool should be maintained at the same as the surface temperature of test device. Therefore, the small pool was placed in an insulated large pool that acted as a constant temperature water bath. The temperature variation of the small pool was controlled within $\pm 0.5^{\circ} \mathrm{C}$.

The test device was first mounted on the positioning mechanism at a fixed tilt angle. By adjusting the height of test device, the adiabatic region of test device would be merged into the working fluid. The working fluid was pumped into the grooves by capillary forces until it arrived at a dryout point. To maintain the evaporating region at a fixed length, the height of test device was adjusted slowly until the dryout point touched the upper edge of grooves. The wetted axial length was then obtained by measuring the distance from the evaporating region to the upper edge of groove with a reading error of $\pm 1.0 \mathrm{~mm}$. Since the surface roughness might have a variance among each microgroove, the maximum axial wetted length of each microgroove might be different; therefore, an averaged value among the 50 microgrooves was recorded.

\section{Results and discussions}

The influence of surface characteristics on the maximum wetted axial length $\left(x_{\max }\right)$ is investigated in the present study. The result of the present experimental work is compared with the values of $x_{\max }$ obtained from the algebraic equation previously presented by Peterson and $\mathrm{Ha}[18]$ : 
$x_{\max }=\frac{r_{\mathrm{j}}}{2 A}\left(-B r_{\mathrm{j}}^{3}+\sqrt{B^{2} r_{\mathrm{j}}^{6}+8 A r_{\mathrm{j}}}\right)$,

where

$A=\frac{4 K v_{1} q_{\mathrm{b}}^{\prime \prime} W}{C \sigma h_{f g}} \quad$ and $\quad B=\frac{\rho g \sin \beta}{\sigma}$,

$C=4 \tan ^{2} \alpha\left(\frac{1}{\tan \alpha}+\alpha-\frac{\pi}{2}\right)^{3}$.

The axial length, $x_{\max }$, is a function of $r_{\mathrm{j}}$, A, and $\mathrm{B}$. The radius of curvature at the junction, $r_{\mathrm{j}}$, can be found by analyzing the liquid film behavior in the adiabatic region.

The nonlinear differential equation of the adiabatic region is expressed as

$\frac{\mathrm{d} r\left(x^{\prime}\right)}{\mathrm{d} x^{\prime}}=-\frac{A x_{\max }}{r\left(x^{\prime}\right)^{2}}-B r\left(x^{\prime}\right)^{2}$.

Since the meniscus completely fills the groove at the origin, the applicable boundary condition becomes

at $\quad x^{\prime}=0, \quad r\left(x^{\prime}\right)=r_{0}=\frac{W}{\cos \alpha}$.

The value of $r_{\mathrm{j}}$ that is numerically found by Eqs. (4) and (5) can then be substituted into Eq. (1) to solve the value of $x_{\max }$.

The test devices used in the measurement include a non-etched microgrooves plate and an etched microgrooves plate. The SEM micrographs of the non-etched microgrooves texture in Figs. 5(a) and 6(a) show that the microgrooves surface is covered with lined incisions. As shown in these micrographs, most of these incisions are parallel to the machining direction, which is also the axial direction of microgrooves. Therefore, it is believed that the friction between the cutting tool and the copper plate has formed these lined incisions. As shown in Figs. 5(b) and 6(b), the surface texture of the etched microgrooves plate was rough with chemical etching using nitric acid solution. The lined incisions caused by cutting tool become less obvious as compared with Fig. 5(a). The texture of the etched surface is clearly showed in Fig. 6(b). Micro cavities of sub-micron range are evenly distributed over the microgrooves surface etched by nitric acid solution.

The micrographs shown in Figs. 5 and 6 reveal the qualitative observation. However, the actual dimension of the surface roughness cannot be quantitatively determined. Therefore, a further quantitative analysis was performed by a non-destructive surface profilometer to measure the surface roughness. The principle of the profilometer is to optically determine the dimension of roughness by interference patterns. For the present tested triangular microgrooves, the measurement becomes difficult due to the inclined microgroove surfaces. Therefore, the microgrooves plate has to be inclined to form an observable interference patterns. The measured average roughness $\left(R_{\mathrm{a}}\right)$ is $0.391 \mu \mathrm{m}$ for the non-etched microgrooves plate, and $0.333 \mu \mathrm{m}$ for the etched mi- (a) non-etched surface

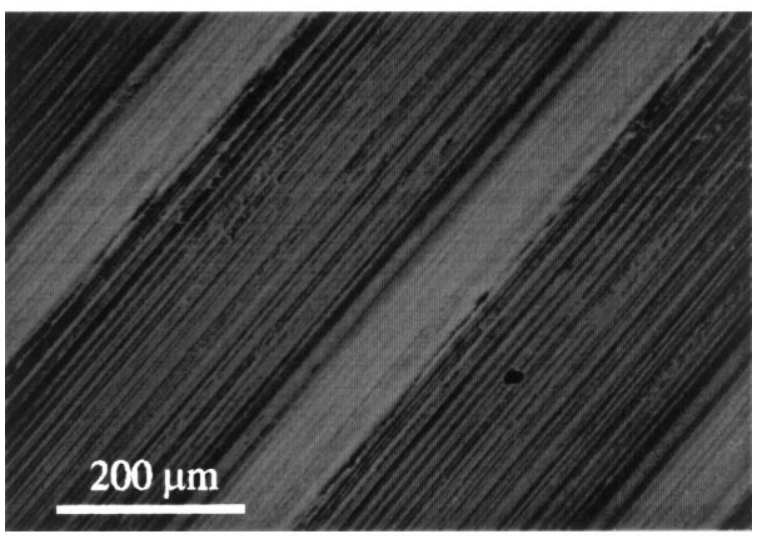

(b) etched surface

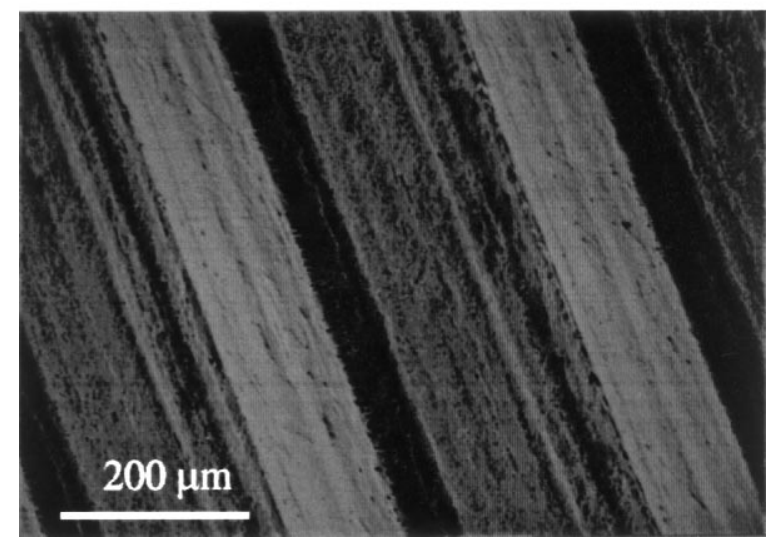

Fig. 5. Scanning electron micrographs of microgrooves surface texture $(\times 101)$.

crogrooves plate. From the qualitative analysis, the micrographs of the etched and non-etched surfaces show that the surface texture and profile is totally different for the two cases. However, the quantitative analysis shows that the two different textures have a very close average roughness value.

The effect of inclination angle $(\beta)$ on the maximum wetted axial length $\left(x_{\max }\right)$ for working fluids of methanol and ethanol are shown in the following figures with two heat flux values for each case. Figs. 7 and 8 show the results for methanol with heat flux of 5150 and $8070 \mathrm{~W} / \mathrm{m}^{2}$, respectively, and Figs. 9 and 10 show the cases for ethanol with heat flux of 3670 and 5480 $\mathrm{W} / \mathrm{m}^{2}$, respectively. The values of heat flux and tilt angle are restricted to the present experimental setup. The square box is used as the symbol for the measured results of the non-etched microgrooves surface, and the hollow circle represents the etched surface. The baseline check is made with the calculated results of the algebraic equation derived by Peterson and $\mathrm{Ha}$ [18] that is shown by solid line in each figure. In Figs. 7-10, the values of $x_{\max }$ show the trend of decrease with increased inclination angle. The predicted value of the algebraic 
(a) non-etched surface

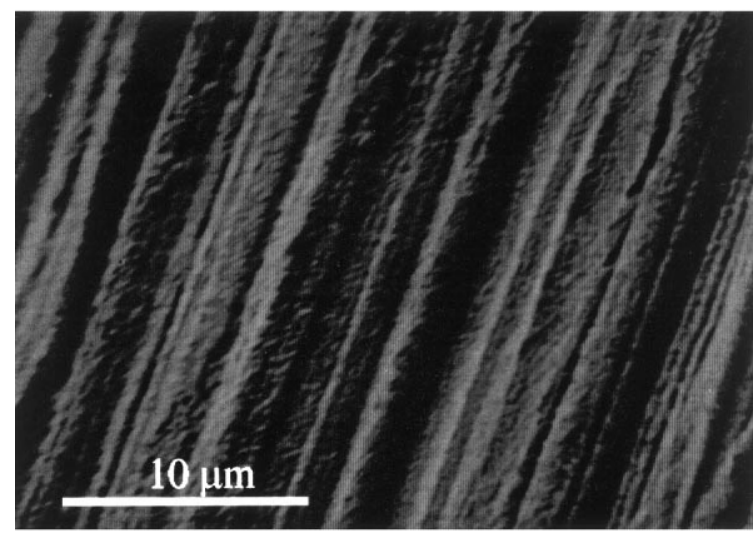

(b) etched surface

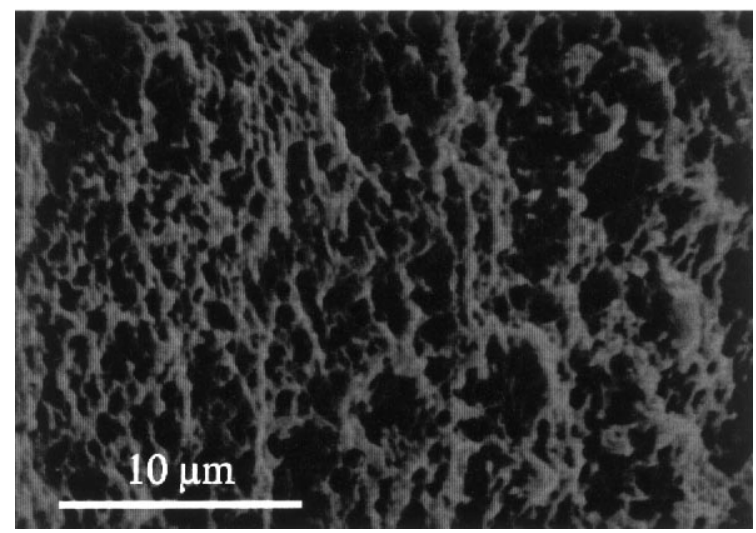

Fig. 6. Scanning electron micrographs of microgrooves surface texture $(\times 2980)$.

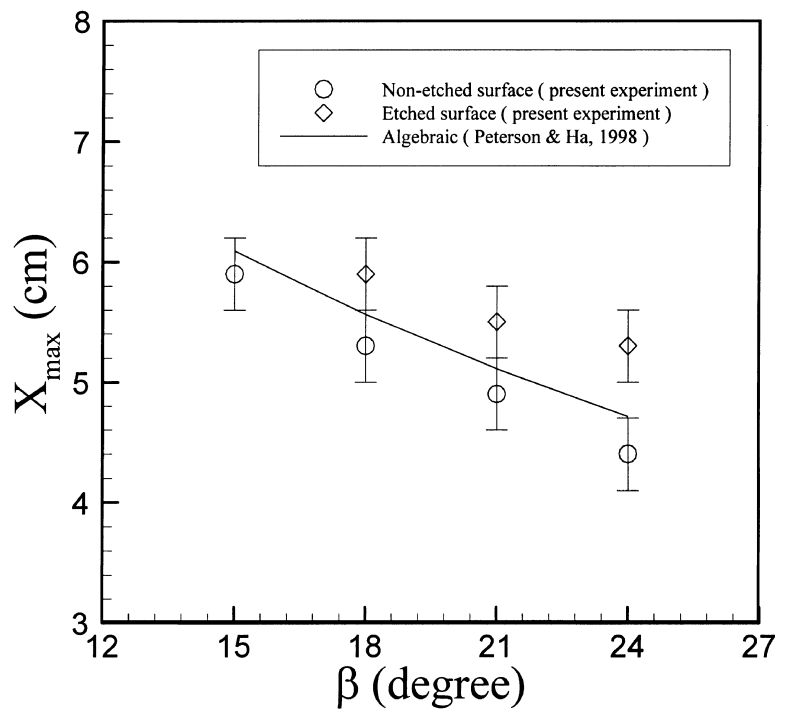

Fig. 7. Wetted axial length for methanol, $q_{\mathrm{b}}^{\prime \prime}=5150 \mathrm{~W} / \mathrm{m}^{2}$, $T_{\text {sat }}=49^{\circ} \mathrm{C}$.

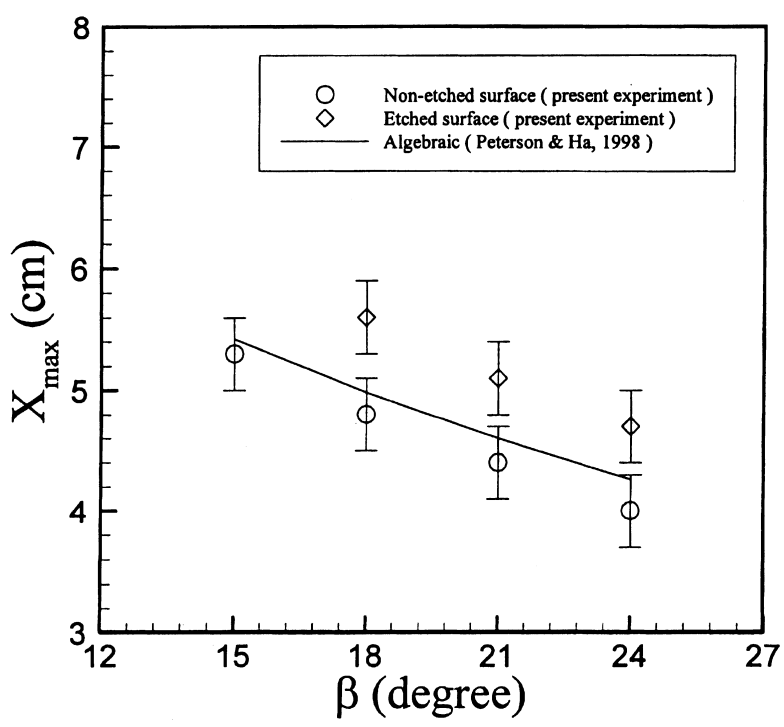

Fig. 8. Wetted axial length for methanol, $q_{\mathrm{b}}^{\prime \prime}=8070 \mathrm{~W} / \mathrm{m}^{2}$, $T_{\text {sat }}=57^{\circ} \mathrm{C}$.

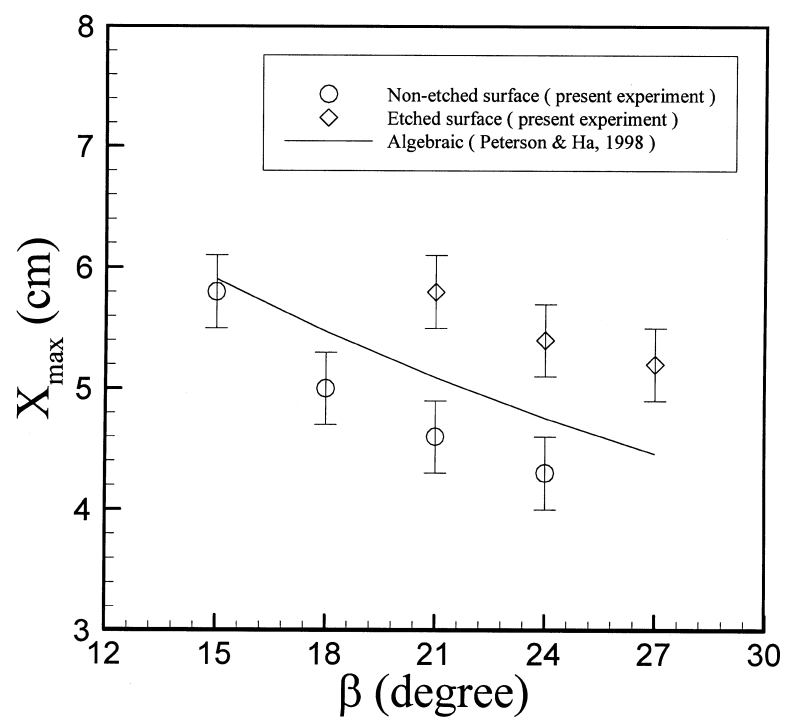

Fig. 9. Wetted axial length for ethanol, $q_{\mathrm{b}}^{\prime \prime}=3670 \mathrm{~W} / \mathrm{m}^{2}, T_{\text {sat }}=50^{\circ} \mathrm{C}$.

equation lies between non-etched case and etched case of the experimental data at all inclination angles. The algebraic prediction has $x_{\max }$ values higher than the nonetched surface of the experimental data. For the measured results at all applied heat flux values, the $x_{\max }$ of the etched surface has a value of $10-20 \%$ higher than the non-etched surface for methanol (Figs. 7 and 8), and $25-35 \%$ for ethanol (Figs. 9 and 10). The higher values of $x_{\max }$ for the etched surface show that the capillary performance has been improved by the surface texture.

As mentioned previously, both the adhesive force and the capillary force are the dominant forces in the evaporating thin film region. The surface of 


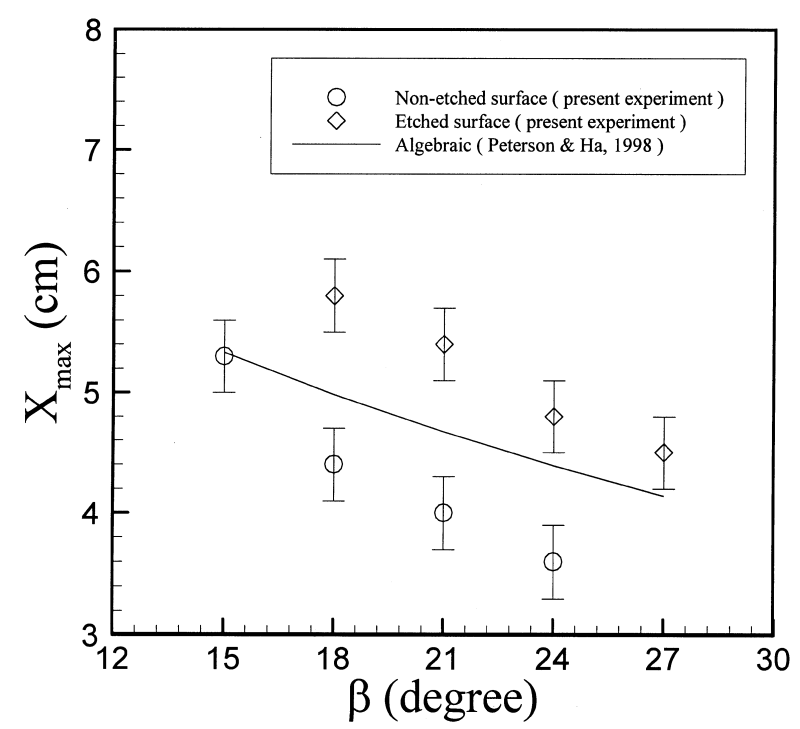

Fig. 10. Wetted axial length for ethanol, $q_{\mathrm{b}}^{\prime \prime}=5480 \mathrm{~W} / \mathrm{m}^{2}$, $T_{\text {sat }}=59^{\circ} \mathrm{C}$.

microgroove became rough with distributed micro cavities after etching. These micro cavities have a dimension of the same order or even smaller order (submicron) to the interline region of thin liquid film. Hence, the force balance between the adhesive force of the liquid/solid and the cohesive force in the liquid has been changed. The cohesive force in the thin liquid film is then decreased due to the existence of these micro cavities. That is, the adhesive force between the liquid film and solid surface has been relatively raised, and a better liquid/solid wettability is formed. Consequently, a longer wetted axial length of microgroove that indicates an improved capillary performance will be observed. It is no doubt that surface roughness is an important parameter of the surface wettability. However, the present experimental results show that the effect of surface texture is more obvious because the measured average roughness of the non-etched surface $(0.391 \mu \mathrm{m})$ has found to be close to the value of the etched surface $(0.333 \mu \mathrm{m})$. It is obvious that the etched microgrooves surface texture covered with micro cavities can effectively increase the wettability as compared to the non-etched surface texture covered with lined incisions.

The effect of surface characteristics on the wettability of different working fluids is discussed. Methanol and ethanol, which are both low free energy liquid and highly wetting flow, were used as the working fluid. The results show that the surface characteristics have different influences on the two working fluids. In the cases of methanol (Figs. 7 and 8), the capillary performance of the etched surface is increased in a range of $10-20 \%$ for both applied heat flux values. However, a higher increase of $25-35 \%$ can be achieved for the cases of ethanol (Figs. 9 and 10). The discrepancy might be caused by the higher surface tension of methanol.

\section{Conclusions}

The present study explores the vaporization process of thin liquid film in triangular microgrooves (with vertex angle of $60^{\circ}$ ) through experimental method, and also verifies the theoretical model presented by Peterson and $\mathrm{Ha}$ [18]. The maximum wetted axial length $\left(x_{\max }\right)$ was measured under the variations of the tilt angle, the applied heat flux, thermophysical properties of working fluid, and surface characteristics of the microgrooves. For the etched microgrooves surface, the texture with micro cavities has increased the capillary performance by $10-35 \%$ as compared to the non-etched surface. The surface characteristic is proved to have more obvious influences on the capillary performance of working fluid with lower surface energy. The present result shows that the change of surface texture performed by chemical etching is effective in increasing the capillary performance of microgrooves, especially when a low surface tension working fluid is used. Therefore, for the capillary flow problems of microgrooves, the surface texture is proved to be an important parameter that decides the capillary performance.

\section{References}

[1] D. Plesch, W. Bier, D. Seidel, K. Schubert, Miniature heat pipes for heat removal from microelectronic circuits, in: D. Cho, R. Arrington, Jr., et al., (Eds.), Micromechanical Sensors, Actuators, and Systems, DSC-vol. 32, ASME, New York, 1991, pp. 303-313.

[2] G.P. Peterson, An overview of micro heat pipe research, ASME Applied Mechanics Reviews 45 (1992) 175-189.

[3] F.W. Holm, S.P. Goplen, Heat transfer in the meniscus thin-film transition region, ASME Journal of Heat Transfer 101 (1979) 498-503.

[4] F.J. Renk, P.C. Wayner Jr., An evaporating ethanol meniscus. Part I: Experimental studies, ASME Journal of Heat Transfer 101 (1979) 55-58.

[5] M. Potash, P.C. Wayner Jr., Evaporation from a two-dimensional extended meniscus, International Journal of Heat and Mass Transfer 15 (1972) 1851-1863.

[6] P.C. Wayner Jr., Y.K. Kao, L.V. LaCroix, The interline heattransfer coeffiecient of an evaporating wetting film, International Journal of Heat and Mass Transfer 19 (1976) 487-492.

[7] F.J. Renk, P.C. Wayner Jr., An evaporating ethanol meniscus. Part II: Analytical studies, ASME Journal of Heat Transfer 101 (1979) 59-62.

[8] A. Mirzamoghadam, I. Catton, A physical model of the evaporating meniscus, ASME Journal of Heat Transfer 110 (1998) 201-207.

[9] J.A. Schonberg, P.C. Wayner Jr., Analytical solution for the integral contact line evaporative heat sink, Journal of Thermophysics 6 (1) (1992) 128-134.

[10] S. DasGupta, J.A. Schonberg, P.C. Wayner Jr., Investigation of an evaporating extented meniscus based on the augmented Young-Laplace equation, ASME Journal of HeatTransfer 115 (1993) 201-214.

[11] P. Ayyaswamy, S.I. Catton, D.K. Edwards, Capillary flow in triangular grooves, ASME Journal of Applied Mechanics 41 (1974) 332-336. 
[12] P.C. Stephan, C.A. Busse, Analysis of the heat transfer coefficient of grooved heat pipe evaporator walls, International Journal of Heat and Mass Transfer 35 (2) (1992) 383-391.

[13] D. Khrustalev, A. Faghri, Heat transfer during evaporation on capillary-grooved structures of heat pipes, ASME Journal of Heat Transfer 117 (1995) 740-747.

[14] J.M. Ha, G.P. Peterson, Analytical prediction of the axial dryout point for evaporating liquids in triangular microgrooves, ASME Journal of Heat Transfer 116 (1994) 498-503.

[15] J.M. Ha, G.P. Peterson, Capillary performance of evaporating flow in micro grooves: an analytical approach for very small tilt angles, ASME Journal of Heat Transfer 120 (1998) 452-457.

[16] X. Xu, V.P. Carey, Film evaporation from a micro-grooved surface - an approximate heat transfer model and its comparison with experimental data, AIAA Journal of Thermophysical and Heat Transfer 4 (4) (1990) 512-520.

[17] G. Stroes, T. Rohloff, I. Catton, An Experimental Study of the Capillary Forces in Rectangular Channels vs Triangular Channels, HTD 301, ASME, New York, 1992, pp. 1-8.

[18] G.P. Peterson, J.M. Ha, Capillary performance of evaporating flow in micro grooves: an approximate analytical approach and experimental investigation, ASME Journal of Heat Transfer 120 (1998) 743-751.

[19] T.S. Sheu, P.P. Ding, P.H. Chen, Numerical and experimental study of capillary forces in trapezoid microgrooves, in: SPIE Conference on Microfluidic Devices and Systems II, SPIE-vol. 3877, Santa Clara, CA, 1999, pp. 295-302. 